\title{
Anion Dependence of Rabbit Medullary Collecting
}

\section{Duct Acidification}

\author{
D. K. Stone, D. W. Seldin, J. P. Kokko, and H. R. Jacobson, Department of \\ Internal Medicine, The University of Texas Health Science Center, \\ Dallas, Texas 75235
}

\begin{abstract}
A B S T R A C T Rabbit medullary collecting duct (MCD) acidification has been demonstrated to occur by means of a sodium-independent, aldosterone-stimulated mechanism. We have examined the anionic dependence of this process by means of the isolated perfused tubule technique. Total replacement of perfusate chloride with gluconate enhanced tubular bicarbonate reabsorption $\left(\mathrm{JHCO}_{3}\right)$, from a basal rate of $10.7 \pm 1.0$ $\mathrm{pmol} \cdot \mathrm{mm}^{-1} \cdot \mathrm{min}^{-1}$ to a rate of $15.01 \pm 1.0 \mathrm{pmol} \cdot$ $\mathrm{mm}^{-1} \cdot \mathrm{min}^{-1}$. Removal of bath chloride, with and without removal of perfusate chloride completely abolished acidification. Bath, but not luminal 4-acetamido-4' isothiocyano-2,2'-disulfonic stilbene provoked a marked decrease in $\mathrm{JHCO}_{3}$ from $10.1 \pm 1.2$ $\mathrm{pmol} \cdot \mathrm{mm}^{-1} \cdot \mathrm{min}^{-1}$ to $2.3 \pm 0.3 \mathrm{pmol} \cdot \mathrm{mm}^{-1} \cdot \mathrm{min}^{-1}$. Measurement of chloride reabsorptive rate $(\mathrm{JCl})$ revealed colinearity between $J_{\mathrm{HCO}_{3}}(9.18 \pm 0.9 \mathrm{pmol}$. $\left.\mathrm{mm}^{-1} \cdot \mathrm{min}^{-1}\right)$ and $\mathrm{JCl}\left(9.75 \pm 1.18 \mathrm{pmol} \cdot \mathrm{mm}^{-1}\right.$. $\left.\min ^{-1}\right)$. We propose a model of mammalian distal nephron acidification in which $(a)$ cellular base exit is effected by means of a basolateral membrane $\mathrm{Cl}$ base exchanger and $(b)$ net electroneutrality of electrogenic proton secretion is maintained by the parallel movement of an anionic species, functionally chloride.
\end{abstract}

Received for publication 3 January 1983 and in revised form 3 February 1983.

\section{INTRODUCTION}

Acidification in rabbit medullary collecting duct (MCD) ${ }^{1}$ perfused in vitro is effected by means of an aldosterone-modulated mechanism that appears to be independent of sodium $(1,2)$. With the demonstration that MCD from inner stripe of outer medulla reabsorbs bicarbonate at a rate of $>10 \mathrm{pmol} \cdot \mathrm{mm}^{-1} \cdot \mathrm{min}^{-} \cdot(3)$, but has negligible net potassium secretory or chloride reabsorptive capacity (4), it appears that the spontaneously lumen-positive voltage characteristic of this segment derives from a primary, electrogenic, proton current. In support of this is the demonstration that acetazolamide abolishes both bicarbonate reabsorption and the lumen-positive voltage (3). A similar acidification process has been described in the turtle bladder (5), a model epithelium closely paralleling the collecting duct functionally.

Such an electrogenic proton secretory mechanism requires the net reabsorption of a positively charged species and/or the parallel conductance of an anionic species to maintain electroneutrality. Furthermore, this model requires a mechanism for the disposal of intracellular base, which accrues as a function of pro-

${ }^{1}$ Abbreviations used in this paper: JCl, net chloride flux $J_{v}$, net volume; MCD, medullary collecting duct; SITS, 4acetamido-4' isothiocyano-2,2'-disulfonic stilbene; $V_{T}$, transepithelial voltage. 
ton secretion. Recently, evidence has been provided for a basolateral membrane $\mathrm{Cl}$-base exchanger in turtle bladder (6).

The present study examines the anionic dependence of MCD acidification and the nature of the ionic species balancing electrogenic proton secretion.

\section{METHODS}

MCD segments from inner stripe of outer medulla of female New Zealand white rabbits were dissected and perfused in vitro as previously described (7). Inner stripe of outer medulla was defined by dissecting three pars recta to their points of tapering to thin descending limbs. The lowest point of taper defined the proximal limit of the region from which MCD were harvested and the distal limit was defined by the junction of red and white medulla. Tubule length averaged $1.45 \mathrm{~mm}$ and was not statistically different among protocol groups.

Bicarbonate reabsorption was measured by microcalorimetry (8) and net chloride flux was assayed electrometrically (9) (W-P Instruments, New Haven, CT). Two to three measurements were made per experimental maneuver and chloride collections were bracketed by bicarbonate determinations. $\left[{ }^{3} \mathrm{H}\right]$ Inulin was added to perfusate as a volume marker. No tubule was accepted with a $J_{0} \geqq 0.05 \mathrm{nl} \cdot \mathrm{mm}^{-1} \cdot \mathrm{min}^{-1}$. In all protocols involving bath and perfusate substitutions or additions, tubule perfusion rate averaged $3.55 \mathrm{nl} / \mathrm{min}$. There was no significant difference in perfusion rates during the various maneuvers. During experiments comparing the bicarbonate reabsorptive rate $\left(J \mathrm{HCO}_{3}\right)$ and the chloride flux rate $(J \mathrm{Cl})$, perfusion rates averaging $1.81 \mathrm{nl} / \mathrm{min}$ were utilized. Constant volume pipettes between 35 and $41 \mathrm{nl}$ were used for all flux measurements.

Two bath and perfusate solutions were utilized in the protocols: (a) $115 \mathrm{~mm} \mathrm{Cl}$ solution, a $\mathrm{HCO}_{3}$ Ringer's solution $\left(\mathrm{NaCl} 105 \mathrm{mM}\right.$, KCL $5 \mathrm{mM}, \mathrm{NaHCO}_{3} 25 \mathrm{mM}$, Na acetate $10 \mathrm{mM}, \mathrm{CaCl}_{2} 2.4 \mathrm{mM}, \mathrm{Na}_{2} \mathrm{HPO}_{4} 2.5 \mathrm{mM}, \mathrm{MgSO}_{4} 1 \mathrm{mM}$, alanine $5 \mathrm{mM}$, glucose $8.3 \mathrm{mM}$ ) and, (b) $0 \mathrm{Cl}^{-}$solution ( $\mathrm{Na}$ gluconate $105 \mathrm{mM}$, K gluconate (both from Sigma Chemical Co., St. Louis, MO) $5 \mathrm{mM}, \mathrm{NaHCO}_{3} 25 \mathrm{mM}$, Na acetate 2.5 $\mathrm{mM}, \mathrm{Ca}$ acetate $_{2} 2.4 \mathrm{mM}, \mathrm{Na}_{2} \mathrm{HPO}_{4} 2.5 \mathrm{mM}, \mathrm{MgSO}_{4} \mathrm{l} \mathrm{mM}$, alanine $5 \mathrm{mM}$, glucose $8.3 \mathrm{mM}$ ). All solutions were equilibrated with $95 \% \mathrm{O}_{2}, 5 \% \mathrm{CO}_{2}$ at $37^{\circ} \mathrm{C}$ to a final $\mathrm{pH}$ of 7.4. Bath was supplemented with $5 \%$ fetal calf serum except when $0 \mathrm{Cl}^{-}$solution was used as bath. No inulin was added when $0 \mathrm{Cl}^{-}$solution was used as perfusate. The anion transport inhibitor 4-acetamido-4' isothiocyano-2,2'-disulfonic stilbene, SITS (Polysciences, Inc., Warrington, PA), was added in a final concentration of $5 \times 10^{-4} \mathrm{M}$ to bath or perfusate, as protocol dictated.

Transepithelial voltage $\left(V_{T}\right)$ was measured by means of a circuit using a Ringer's solution/agarose bridge system (10). Liquid junction potentials, generated by contact between the Ringer's containing bridge and $0 \mathrm{Cl}^{-}$solution, were measured using $\mathrm{KNO}_{3} / \mathrm{KCl}$ agarose bridges as described previously $(10,11)$. The measured liquid junction potential between normal $(115 \mathrm{mM}) \mathrm{Cl}^{-}$solution and $0 \mathrm{Cl}^{-}$ solution was $6.8 \mathrm{mV}$. All voltage measurements during which either perfusate or bath was $\mathrm{O} \mathrm{Cl}^{-}$solution have been corrected for this liquid junction potential.

Chloride diffusion potentials across medullary collecting duct were determined by cooling the tubule to $21^{\circ} \mathrm{C}$ (a maneuver that reduced the lumen-positive voltage to values not significantly different from zero) with $115 \mathrm{mM} \mathrm{Cl}$ solution as perfusate and bath. Then the bath was changed from $115 \mathrm{mM}$ chloride solution to $0-\mathrm{Cl}$ solution. The diffusion potential (after correction for liquid junction potential) was $7.55 \mathrm{mV}$. This diffusion potential was symmetrical in that similar values were observed when perfusate was changed to $0 \mathrm{Cl}^{-}$solutions at $21^{\circ} \mathrm{C}$.

Cl permeability was derived in the following manner: tubules were perfused at $21^{\circ} \mathrm{C}$ with $115 \mathrm{mM} \mathrm{Cl}, 140 \mathrm{mM} \mathrm{Na}$ solution as described above, and bathed in an identical solution. The bath or perfusate was then changed to a solution containing $40 \mathrm{mM} \mathrm{Cl}$ and $65 \mathrm{mM} \mathrm{Na}$ (i.e., a $75-\mathrm{mM} \mathrm{NaCl}$ gradient was induced). Osmotic balance between perfusate and bath was maintained by replacing the $\mathrm{NaCl}$ with raffinose. The resultant diffusion potential (corrected by the liquid junction potential) was utilized to calculate the relative $\mathrm{Na}$ to $\mathrm{Cl}$ permeability via the modified Goldman equation as described previously (10). Using a $\mathrm{Na}$ permeability for MCD of $0.4 \times 10^{-5} \mathrm{~cm} \cdot \mathrm{s}^{-1}$, as reported by Stokes (12) the calculated $P_{\mathrm{Cl}}$, so obtained was $P_{\mathrm{Na}} \times 1.2$ or 0.48 $\times 10^{-5} \mathrm{~cm} \cdot \mathrm{s}^{-1}$.

\section{Protocols}

Luminal substitutions. $\mathrm{JHCO}_{3}$ and $\mathrm{V}_{T}$ were measured using $115 \mathrm{mM} \mathrm{Cl}$ bath and perfusate. Perfusate was then changed to $0 \mathrm{Cl}$ solution and repeat $\mathrm{JHCO}_{3}$ and $\mathrm{V}_{T}$ determinations were peformed. In separate experiments, $\mathrm{JHCO}_{3}$ and $V_{T}$ were measured before, and $30 \mathrm{~min}$ after, addition of $5 \times 10^{-4} \mathrm{M}$ SITS to perfusate. Bath and perfusate consisted of $115 \mathrm{mM} \mathrm{Cl}^{-}$throughout the SITS experiments.

Bath substitutions. During continuous perfusion with $115 \mathrm{~m} \mathrm{M} \mathrm{Cl}^{-}$solution, $J \mathrm{HCO}_{3}$ and $V_{T}$ were measured with serial bath compositions of $115 \mathrm{mM} \mathrm{Cl}^{-}, 0 \mathrm{Cl}^{-}$, and $115 \mathrm{mM}$ $\mathrm{Cl}^{-}$. In separate experiments, $J \mathrm{HCO}_{3}$ and $V_{T}$ were measured when both bath and perfusate were $0 \mathrm{Cl}$ solution. Finally, $\mathrm{JHCO}_{3}$ and $V_{T}$ were determined before, and $30 \mathrm{~min}$ after addition of $5 \times 10^{-4} \mathrm{M}$ SITS to bath.

Chloride flux determinations. Utilizing $115 \mathrm{mM} \mathrm{Cl}$ bath and perfusate, $\mathrm{JHCO}_{3}$ and $\mathrm{JCl}$ were sequentially measured to compare flux rates.

\section{RESULTS}

Fig. 1 illustrates the effects of substitution of perfusate $\mathrm{Cl}$ with gluconate and, in separate experiments, addition of SITS to perfusate. As illustrated, removal of perfusate chloride increased $\mathrm{JHCO}_{3}$ significantly from $10.7 \pm 1.0 \mathrm{pmol} \cdot \mathrm{mm}^{-1} \cdot \mathrm{min}^{-1}$ to $15.01 \pm 1.8 \mathrm{pmol} \cdot$ $\mathrm{mm}^{-1} \cdot \mathrm{min}^{-1}$. Although $V_{T}$ corrected for liquid junction potential decreased from $12.9 \pm 4.0$ to $8.7 \pm 3.9 \mathrm{mV}$, the change was not significant. Also shown in Fig. 1, addition of $5 \times 10^{-4} \mathrm{M}$ SITS to perfusate effected no change in either $\mathrm{JHCO}_{3}\left(9.54 \pm 0.86 \mathrm{pmol} \cdot \mathrm{mm}^{-1}\right.$. $\mathrm{min}^{-1}$, control; $9.67 \pm 0.93 \mathrm{pmol} \cdot \mathrm{mm}^{-1} \cdot \mathrm{min}^{-1}$, experimental) or $V_{T}(6.9 \pm 1.0 \mathrm{mV}$, control; $6.7 \pm 0.7 \mathrm{mV}$, experimental).

Fig. 2 illustrates the effects upon $\mathrm{JHCO}_{3}$ and $\mathrm{V}_{T}$ of total bath chloride replacement and, independently, addition of SITS to bath. As can be seen, substitution of gluconate for bath chloride resulted in a reversible ablation of bicarbonate reabsorption $\left(\mathrm{JHCO}_{3} 9.88 \pm 1.1\right.$ $\mathrm{pmol} \cdot \mathrm{mm}^{-1} \cdot \mathrm{min}^{-1}, \quad$ control; $J \mathrm{HCO}_{3}-0.19 \pm 0.19$ $\mathrm{pmol} \cdot \mathrm{mm}^{-1} \cdot \mathrm{min}^{-1}$, experimental; $\mathrm{JHCO}_{3} 10.1 \pm 1.19$ $\mathrm{pmol} \cdot \mathrm{mm}^{-1} \cdot \mathrm{min}^{-1}$, recovery). The lumen-positive 


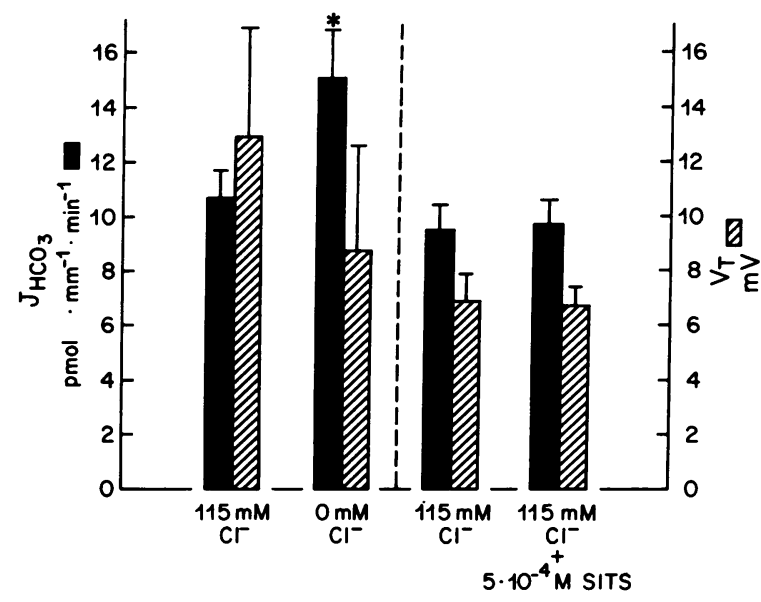

Figure 1

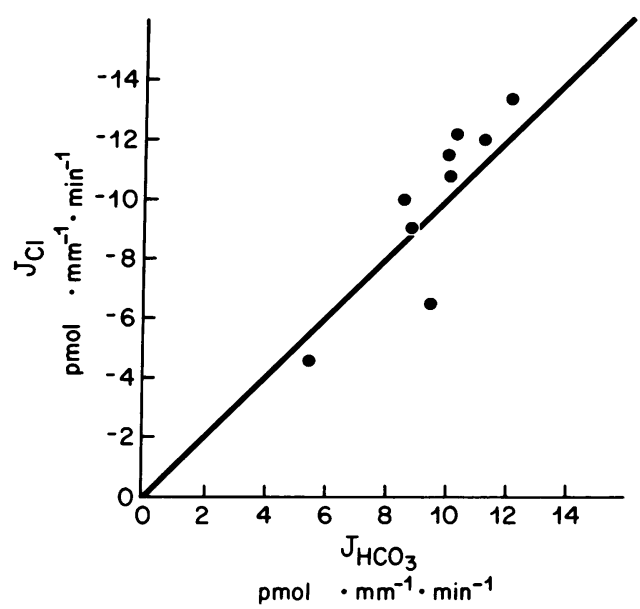

Figure 3 voltage, corrected for liquid junction potential, did not change significantly $(10.5 \pm 2.0 \mathrm{mV}$, control; $8.7 \pm 0.7$ $\mathrm{mV}$, experimental) with this maneuver. In experiments not illustrated $(n=4)$, tubules subjected to $0 \mathrm{Cl}^{-}$bath and perfusate demonstrated very low $\mathrm{JHCO}_{3}$ and $V_{T}$ $\left(0.8 \pm 0.1 \mathrm{pmol} \cdot \mathrm{mm}^{-1} \cdot \mathrm{min}^{-1}\right.$ and $1.8 \pm 0.2 \mathrm{mV}$, respectively). Bath SITS at $5 \times 10^{-4} \mathrm{M}$ prompted a nonreversible fall in both $\mathrm{JHCO}_{3}$ and $V_{T}$ to values, respectively, 22 and $23 \%$ of control, as shown in Fig. 2.

Finally, Fig. 3 illustrates the relationship of net bicarbonate flux to net chloride flux in tubules perfused and bathed with $115 \mathrm{mM} \mathrm{Cl}$ solutions. As can be seen, there is colinearity in the rates of bicarbonate reabsorption and chloride secretion with rates of $9.18 \pm 0.9$ $\mathrm{pmol} \cdot \mathrm{mm}^{-1} \cdot \mathrm{min}^{-1}$ and $9.75 \pm 1.19 \mathrm{pmol} \cdot \mathrm{mm}^{-1}$. $\min ^{-1}$, respectively.

\section{DISCUSSION}

The present studies define a mechanistic role for $\mathrm{Cl}^{-}$ in the process of medullary collecting duct acidifi-

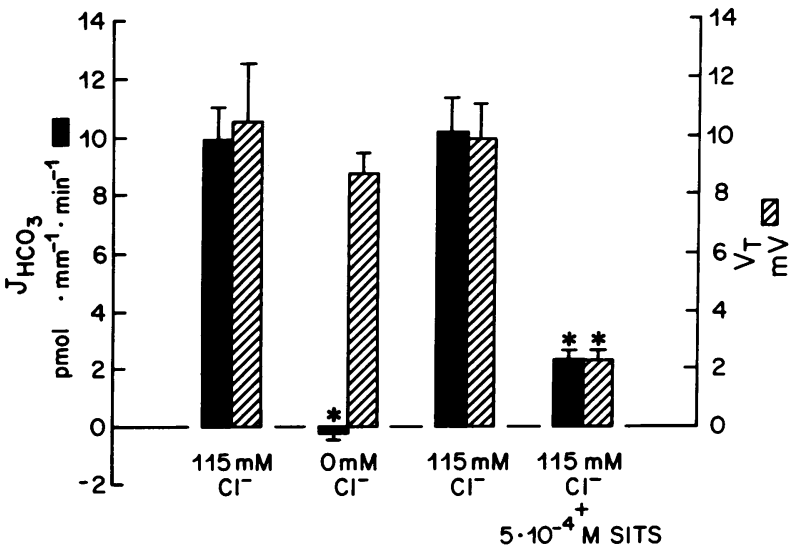

Figure 2 cation. Removal of luminal chloride enhanced bicarbonate reabsorption. In these studies there was a trend (although not statistically significant) for the lumenpositive voltage to become less positive owing to a bath to lumen $\mathrm{Cl}$ diffusion potential. Such a diffusion potential, by lowering the lumen-positive voltage, would favor electrogenic proton secretion. Whether this is the mechanism for the enhanced bicarbonate reabsorption seen with luminal $\mathrm{Cl}^{-}$replacement is still unclear. It should be noted that correction of the observed voltage $(8.7 \mathrm{mV})$ by the bath to lumen $\mathrm{Cl}^{-}$diffusion potential $(7.6 \mathrm{mV})$ that is present when $0 \mathrm{Cl}^{-}$ solution is in the lumen results in a $V_{T}$ that, compared with control circumstances, is more lumen positive.

In contrast to luminal $\mathrm{Cl}^{-}$replacement, bath $\mathrm{Cl}^{-}$ replacement ablated bicarbonate reabsorption. Again, lumen positive voltage did not change significantly but tended to decline. However, in these experiments a lumen-positive $\mathrm{Cl}$ diffusion potential exists owing to the large chemical gradient for $\mathrm{Cl}^{-}$from perfusate to bath. Correction of the observed voltage for this $\mathrm{Cl}^{-}$ diffusion potential results in a calculated $V_{T}$ of only $1.1 \mathrm{mV}$. These observations strongly suggest a requirement for chloride on the basolateral surface of medullary collecting ducts. Indeed, the additional demonstration that symmetric removal of chloride from perfusate and bath ablates bicarbonate reabsorption and reduces lumen-positive voltage to a value not different from that calculated above during only bath $\mathrm{Cl}^{-}$replacement ( 1.8 vs. $1.1 \mathrm{mV}$ ) confirms a critical role for peritubular $\mathrm{Cl}^{-} .^{2}$ It is important to note that

${ }^{2}$ The present studies were designed to examine a $\mathrm{Cl}^{-}$effect by replacing $\mathrm{Cl}^{-}$with an anion that was unlikely to be an effective substitute (gluconate). The possibility that other anions such as $\mathrm{Br}^{-}, \mathrm{SO}_{4}^{-}, \mathrm{NO}_{3}^{-}$etc. could partially or completely substitute for $\mathrm{Cl}^{-}$is interesting and remains to be tested. 
during our chloride substitution experiments we measured transepithelial voltage changes. The possibility exists that replacement in perfusate and/or bath produced significant changes in apical or basolateral membrane voltages in addition to diffusion voltages across the paracellular shunt pathway. The magnitude of cell membrane voltages changes and their impact on acidification will require further studies utilizing intracellular electrodes.

Our further observation that basolateral, but not luminal, SITS markedly reduces acidification and lumen-positive voltage supports the notion that peritubular chloride is instrumental to medullary collecting duct acidification via its participation in a basolateral membrane chloride-base exchanger. Thus intracellular base, which accrues as a result of proton translocation into tubular lumen requires peritubular $\mathrm{Cl}^{-}$for its extrusion from the cell.

Under the conditions of the present study chloride secretion occurred at a rate equal to proton secretion. Such a colinearity would not be predicted given the similarities of the passive permeabilities $\left(\times 10^{-5} \mathrm{~cm}\right.$. $\left.\mathrm{s}^{-1}\right)$ of sodium $\left(P_{\mathrm{Na}}=0.4\right)$ and chloride $\left(P_{\mathrm{Cl}}=0.48\right)$ determined in MCD. If electrogenic acidification were counterbalanced by passive conductances of sodium, potassium and chloride as functions of their measured passive permeabilities and chemical potentials, then both net reabsorption of $\mathrm{Na}^{+}$and net secretion of $\mathrm{Cl}^{-}$ should occur. Indeed, $\mathrm{JHCO}_{3}$ should be about twice $\mathrm{JCl}$ owing to voltage-induced sodium reabsorption (Because $[\mathrm{K}]=5 \mathrm{mM}$, in perfusate and bath the distribution of this species driven by the lumen-positive voltage would be rapidly diminished by the generation of a significant chemical potential $\left.[\mathrm{K}]_{\text {bath }}>[\mathrm{K}]_{\text {lumen }}\right)$. Our finding that $\mathrm{JHCO}_{3}$ and $\mathrm{JCl}$ matched under the present conditions suggest that the MCD may preferentially utilize $\mathrm{Cl}^{-}$to shunt electrogenic acidification. This is corroborated by the finding of Stokes (4) that MCD has no significant $\mathrm{Na}$ reabsorptive capacity under similar conditions. These observations are compatible with the possibility that chloride conduc-

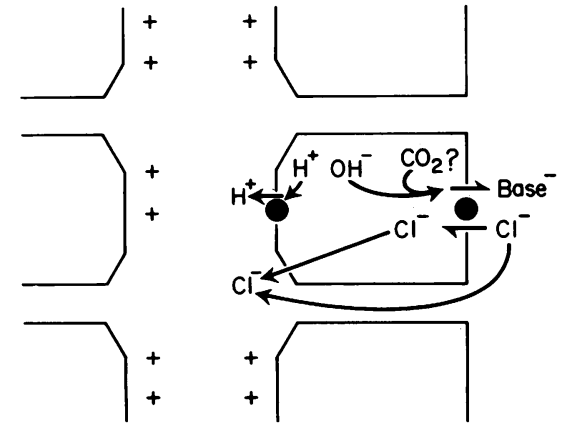

Figure 4 tance during acidifying conditions differs from the passive conductance measured at $21^{\circ} \mathrm{C}$. To explain this, transcellular movement of $\mathrm{Cl}$ is a likely event. Such plasma membrane chloride conducting channels have been described in neuronal tissues (13). A formulation of MCD acidification, incorporating the findings of the present studies is depicted in Fig. 4.

In summary, MCD acidification functionally requires chloride in order to promote basolateral chloride-base exchange and to balance electrogenic proton secretion.

\section{ACKNOWLEDGMENTS}

The authors acknowledge the skillful technical assistance of Ms. Susan Corona and Ms. Amy Womack. Our secretarial assistance was provided by Ms. Cathrine Schmid.

This work was supported in part by National Institutes of Health research grants 5-R01-AM-23901 and 5-R01-AM14677. Harry R. Jacobson is the recipient of National Institutes of Health Research Career Development Award 1-K04AM-00537.

\section{REFERENCES}

1. Stone, D. K., J. P. Kokko, and H. R. Jacobson. 1982. In vitro stimulation of proton secretion by aldosterone. Kidney Int. 21: 240. (Abstr.)

2. Stone, D. K., J. P. Kokko, and H. R. Jacobson. 1982. Sodium independence of proton secretion in medullary collecting duct. Clin. Res. 30: 464a. (Abstr.)

3. Lombard, W., J. P. Kokko, and H. R. Jacobson. 1983. Bicarbonate transport in cortical and outer medullary collecting tubules. Am. J. Physiol. In press.

4. Stokes, J. B., M. J. Ingram, A. D. Williams, and D. Ingram. 1981. Heterogeneity of the rabbit collecting tubule: localization of mineralocorticoid hormone action in the cortical portion. Kidney Int. 20: 340-347.

5. Al-Awqati, Q. 1978. $\mathrm{H}^{+}$transport in urinary epithelia. Am. J. Physiol. 235: F77-F88.

6. Fischer, J. L., R. F. Husted, and P. R. Steinmetz. 1981. Role of basolateral anion exchange in urinary acidification of the turtle bladder. Clin. Res. 29: 687a. (Abstr.)

7. Burg, M., J. Grantham, M. Abramow, and J. Orloff. 1966. Preparation and study of fragments of single rabbit nephrons. Am. J. Physiol. 210: 1293-1298.

8. Vurek, G., D. Warnock, and R. Corsey. 1975. Measurement of picomole amounts of carbon dioxide by calorimetry. Ann. Chem. 47: 765-767.

9. Ramsay, J. A., R. H. J. Brown, and P. C. Croghan. 1955. Electrometric titration of chloride in small volumes. $J$. Exp. Biol. 32: 822-829.

10. Jacobson, H. R., and J. P. Kokko. 1976. Intrinsic differences in various segments of the proximal convoluted tubule. J. Clin. Invest. 57: 818-825.

11. Warnock, D. G., and V. J. Yec. 1982. Anion permeabilities of the isolated perfused rabbit proximal tubule. Am. J. Physiol. 242: F395-F405.

12. Stokes, J. B. 1982. Sodium and potassium transport across the cortical and outer medullary collecting tubule of the rabbit: Evidence for diffusion across the outer medullary portion. Am. J. Physiol. 242: F514-F520.

13. Chenoy-Marchais, D. $1982 . \mathrm{A} \mathrm{Cl}^{-}$conductance activated by hyperpolarization in Aplysia. Nature (Lond.). 299: $359-361$. 